\title{
MUSEU E FORMAÇÃO CULTURAL: INOVAÇÃO CURRICULAR NA CONTEMPORANEIDADE
}

\author{
Alípio CASALI ${ }^{\mathrm{i}}$ \\ Luciana PASQUALUCCI ${ }^{\text {ii }}$
}

\begin{abstract}
RESUMO
Assumindo que, nas economias de mercado, a cultura tende a ser submetida ao regime do capital, este artigo afirma a indissociabilidade entre cultura e educação e submete a um crivo crítico: as práticas dos Museus que se reduzem a arquivos de objetos reificados; as práticas das Universidades que limitam seu currículo à formação profissional como preparação para o mercado de trabalho; e a redução dos seus respectivos públicos à condição de consumidores culturais. $\mathrm{O}$ artigo fundamenta-se no campo da Museologia Crítica, principalmente em Waldisa Rússio (1984) e em Theodor Adorno (1996), especialmente em seu conceito de formação cultural em contraponto à indústria cultural e à semiformação. Conclusivamente, propõe-se uma prática interativa entre Museus e Universidades em prol da formação cultural crítica de seus públicos.
\end{abstract}

PALAVRAS-CHAVE: Museu; Universidade; Theodor Adorno; Semiformação; Formação cultural.

\author{
MUSEUM AND CULTURAL EDUCATION: \\ CURRICULAR INNOVATION IN CONTEMPORANEITY
}

\begin{abstract}
By assuming that, in market economies, culture tends to be submitted to the capital regime, this article stands the inseparability between culture and education and submits to a critical scrutiny: the practices of Museums reduced to archives of reified objects; the practices of Universities that limit professional training to preparation for the job market; the reduction of their audiences to the condition of cultural consumers. The article is based on the field of Critical Museology, mainly in Waldisa Rússio (1984), and Theodor Adorno (1996), especially in his concept of cultural education in opposition to the cultural industry and semi-education. In conclusion, an interactive practice between Museums and Universities is proposed, in favor of the critical cultural education of their audiences.
\end{abstract}

KEYWORDS: Museum; University; Theodor Adorno; Semi-education; Cultural education.

\footnotetext{
${ }^{\text {i }}$ Doutorado em Educação pela PUC-SP. Pós-Doutor pela Université de Paris-8. Professor Titular do Departamento de Fundamentos da Educação, da PUC-SP. Docente, Pesquisador e Coordenador do Programa de Pós-Graduação em Educação: Currículo, da PUC-SP. E-mail: a.casali@uol.com.br.

ii Doutorado e mestre em Educação: Currículo pela PUC-SP. Professora dos cursos de Patrimônio Cultural: gestão, políticas públicas e memória e de Museologia e formação cultural. E-mail: lucianapasqualucci@gmail.com.
} 


\title{
MUSEO Y FORMACIÓN CULTURAL: INNOVACIÓN CURRICULAR EN LA CONTEMPORANEIDAD
}

\begin{abstract}
RESUMEN
Al presuponer que, en las economías de mercado, la cultura tiende a ser sometida al régimen de capital, este artículo afirma la inseparabilidad entre cultura y educación y somete a un escrutinio crítico: las prácticas de los Museos que se reducen a archivos de objetos reificados; las prácticas de las Universidades que limitan sus currículos a la formación professional como preparación para el mercado laboral; y la reducción de sus respectivos públicos a la condición de consumidores culturales. El artículo se fundamenta en el campo de la Museología Crítica, principalmente en Waldisa Rússio (1984) y Theodor Adorno (1996), especialmente en su concepto de formación cultural en contrapunto a la industria cultural y a la semiformación. En conclusión, se propone una práctica interactiva entre Museos y Universidades en pro de la formación cultural crítica de sus públicos.
\end{abstract}

PALABRAS CLAVE: Museo; Universidad; Theodor Adorno; Semi formación; Formación cultural.

\section{INTRODUÇÃO}

O Museu não ensina a repetir o passado, porém a tirar dele tudo quanto ele nos dá dinamicamente para avançar a cultura dentro de nós, e em transformação dentro do progresso social. Mário de Andrade (2005, p. 30).

La lucha contra los museos tiene algo de quijotesco no sólo porque la protesta de la cultura contra la barbarie queda tan apagada en esa lucha que nadie la oye, porque lleva demasiada esperanza.

Theodor Ludwig Wiesengrund Adorno (1962, p. 199).

O presente artigo desenvolve-se em torno da seguinte ordem argumentativa: (1) A prática de colecionar objetos é ancestral; de algum modo, em parte, ela se liga à igualmente ancestral crença de que certos objetos emanam força "espiritual” própria. (2) O Museu ${ }^{1}$ consagrou-se universalmente como instituição especializada em guardar e promover o valor de objetos e os registros históricos e culturais. (3) A cultura é, originariamente, trabalho humano; e todos os sentidos e os imaginários que ela possa produzir são, em última instância, derivados do trabalho ou a ele relacionados. (4) Nas sociedades organizadas pelo capitalismo tardio: (4a) o trabalho é alienado e produz alienação da consciência dos sujeitos; (4b) as mercadorias aparecem, inclusive aos seus próprios produtores, contraditoriamente, como dotadas de força própria, isto é, como fetiche; (4c) a cultura, em consequência, torna-se igualmente alienada por 
efeito de sua abstração (separação) com relação ao trabalho, e seus objetos e registros resultam igualmente como se fossem dotados de força própria, isto é, fetichizados. (5) Nessas sociedades, a cultura tende a ser submetida ao regime do capital - como indústria cultural, dirão Adorno (2000) e Adorno e Horkheimer (2006). (6) Nessas sociedades, em consequência, a formação cultural dos sujeitos, nas instituições, tende a cumprir-se como semiformação (Halbbildung). O Museu e a Universidade tampouco estão isentos dessa tendência a reduzirem suas funções a serviço da indústria cultural e, portanto, a produzirem alienação e semiformação. (7) Não obstante, do ponto de vista da Teoria Crítica, é possível postular que particularmente o Museu e a Universidade devem atuar cooperativamente no contrafluxo da indústria cultural, de modo a cumprirem a formação cultural dos seus públicos mediante projetos de inovação curricular; e postular que essa formação cultural crítica pode cumprir, assim, uma função política e cultural contra-hegemônica ao vincular cultura e ciência.

Os significados dos objetos de arte e dos objetos históricos não são conteúdos ou atributos a eles inerentes, mas derivados do conhecimento e do reconhecimento acerca do seu valor social, compreendidos no ato e no contexto de sua percepção. Merleau-Ponty (1999) descreveu esse processo com especial sutileza e precisão, explicitando como as estruturas mentais que operam a apreensão dos fenômenos do mundo são também elas produtos de interiorização das estruturas pelas quais esse mesmo mundo se organiza. Essas premissas sugerem, preliminarmente, que, no Museu, as múltiplas identidades oferecidas ao público são provocações e convocações a experiências e vivências que apenas acenam a possíveis significados e sentidos, permitindo ao público elaborar, no ato mesmo de sua percepção, os correspondentes exercícios de sensibilidade e de cognição que os reconhecem e legitimam. Se assim é, o Museu possibilita e requer uma operação mental crítica sobre a realidade, articulando, no eixo temporal, imprevisíveis significações históricas entre o passado e o presente; e, no eixo espacial, a não menos imprevisível diversidade de produções e de manifestações culturais.

Uma certa função formativa junto ao público, assim, ocorreria espontaneamente, em maior ou menor grau, em todo Museu, em consequência também da própria disposição do visitante de ter escolhido posicionar-se ali diante de registros portadores de tais significações e sentidos abertos. E ainda que, por acaso, a disposição do visitante seja a de buscar identidades essenciais e fechadas, cabe ao Museu desfazer tal expectativa e introduzir o visitante no universo surpreendente de suas práticas. 
O cumprimento de todo o potencial dessa função formativa do Museu, porém, dependerá do ordenamento intencional das suas iniciativas para esse sentido. Muitos Museus seguem cumprindo uma função reduzida de instituições predominantemente inertes, colecionadoras e exibidoras de objetos, menosprezando seu potencial de instaurar experiências e vivências ${ }^{2}$ formativas junto a seus públicos. No outro extremo, o excesso de protagonismo que tem se mostrado em diversas instituições contemporâneas sugere o quanto estas, enredadas na indústria cultural, não têm resistido à tendência de espetacularização das artes e da cultura, mimetizando a globalização mercantil das corporações e a espetacularização da mercadoria da qual dependem. Em tais casos, sob a dinâmica da indústria cultural, o fetiche dos objetos de cultura musealizados culmina confundindo-se com o fetiche da mercadoria: resultam duas faces de um mesmo fenômeno. Tal condição institucional tem reduzido em grande parte a sua potência de serem instituições produtoras de cultura e educadoras, na medida em que o efeito desse travestimento institucional induz o seu público à expectativa de nelas encontrar muito entretenimento e pouca formação.

É imperativo examinar até que ponto tal posição caracterizaria uma tendência, e identificar qual contraponto possibilitaria ao sujeito visitante uma experiência cultural formativa. A hipótese crítica desse exame é que, ao agregar à sua narrativa discursos e práticas de indivíduos e de comunidades e desenvolver projetos de produção cultural, mais do que apenas exibir objetos de sua coleção, o Museu pode tornar-se uma instituição com decisivo papel de formação cultural no mundo contemporâneo. Ao promover experiências, vivências e convivências provocativas e incentivar reflexões sobre o presente, o passado, o futuro histórico e a diversidade cultural ao redor, o Museu pode mobilizar uma dimensão estética decisiva para a formação cultural crítica do sujeito em um mundo organizado para o espetáculo, (re)instituindo esse sujeito em seu lugar de protagonista e fonte de sentido cultural.

Ao mesmo tempo, outra instituição, aquela historicamente mais consagrada ao cumprimento acabado da função social de formação científica e cultural dos indivíduos, a saber, a Universidade, vê-se não raro enredada em conflitos semelhantes. As mudanças amplas e profundas nos processos econômicos, sociais, políticos e culturais, de alcance global, vieram desafiando as Universidades a uma reconfiguração de seus processos formativos, postulados sobretudo desde o chamado "Processo de Bologna"3. Não obstante, o que há de reconhecidamente meritório dentre as intenções do processo de Bologna abriu campo a 
iniciativas academicamente menos criteriosas e justificou a disposição de muitas instituições universitárias a adotarem missões redutivas na formação de seu público, a saber: reduzirem-se a instituições de formação profissional no sentido mais restrito do conceito, isto é, em função do mercado de trabalho. Tais reconfigurações têm induzido parte do público jovem e suas famílias à expectativa de uma formação universitária "útill", o que, combinado com a redução do Museu à experiência de entretenimento, explica o paradoxal afastamento recíproco dessas duas instituições, não obstante sua convergência nessa submissão de suas funções ao regime do Mercado, e o consequente esvaziamento da formação cultural de seus públicos.

É imperativo, pois, compreender criticamente quais processos operam subliminarmente nesse duplo reducionismo, para que se possam identificar caminhos para a reconstituição da formação cultural, sobretudo dos jovens, na contemporaneidade, mediante a reaproximação dessas duas instituições.

\section{O OBJETO MUSEALIZADO: MEMÓRIA, RELÍQUIA E FETICHE}

Mircea Eliade (1977) iniciou seu clássico Tratado de História das Religiões descrevendo e analisando o mana dos Melanésios: uma "[...] força misteriosa e activa que possuem alguns indivíduos e geralmente as almas dos mortos e todos os espíritos" (ELIADE, 1986, p. 43-44). Objetos que tivessem entrado em contato com tais indivíduos ou se relacionado de alguma forma com essas almas e espíritos seriam igualmente dotados de mana. Seria da mesma natureza o poder decorrente da posse de "objetos de poder" pelos xamãs nas culturas indígenas americanas (CAMPBELL, 1976).

$\mathrm{Na}$ antiga Grécia, o culto aos heróis também implicava uma veneração de suas relíquias, por crer-se que, de sua proximidade e uso, emanaria alguma força materialmente proveitosa, ademais do prestígio social para seu possuidor. Esse tipo de fenômeno tornou-se clássico com o cristianismo, no culto aos santos e aos mártires, cujos restos (do próprio corpo ou de seus pertences) são guardados em preciosos e suntuosos relicários, ou diretamente enterrados sob altares, a partir de onde contribuiriam para a (re)ligação do humano com o Divino. Assim como no caso do mana, possuir uma relíquia de um santo ou aproximar-se dela, tocá-la, produziria o efeito de incorporação de suas forças sobrenaturais.

A relíquia é um objeto simultaneamente inerte e ativo, e nessa ambivalência reside grande parte do seu valor simbólico. Com efeito, a relíquia existe e preserva-se, em parte, para 
ser passivamente admirada. Seu poder de suscitar admiração reproduz, paradoxalmente, seu poder de interferência no campo do sujeito que, com ela, se relaciona. Pois, enquanto é admirada, e, sobretudo, quando respeitosamente tocada, faz emanar uma força residual do seu passado, que proviria do fato de ter participado de eventos extraordinários, associada ao protagonismo do santo, do herói, do gênio artístico ou do intelectual que a possuiu. A relíquia condensa uma história, é um concreto histórico.

Em uma chave antropológica, ao mesmo tempo que com visão histórica, assim descrevem Ishihara-Brito y Guaján:

Reliquia es como un regalo de una generación antigua a las generaciones actuales y futuras; es un regalo a trasladarse constantemente de generación en generación. La reliquia no sólo deja huellas con sentido sino también conlleva un sentimiento profundo, a veces difícil de comprender y explicar y además traslada mensajes culturales importantes que guardan la memoria de los abuelos (ISHIHARA-BRITO; GUAJÁN, 2012, p. 446).

A relíquia evoca e, até certo ponto, tal como o mito (ELIADE, 1986), repete a história da qual fez parte. Ela arrebata os acontecimentos de seu tempo e de seu entorno como testemunhos do passado para o presente e como provocação ao futuro. A relíquia provoca os sujeitos sensíveis ao respeito; quando portadoras de um valor destacado e amplamente reconhecido, o respeito amplia-se como reverência. A admirabilidade, embora fixada na relíquia ali presente, decorre antes da pessoa dos protagonistas passados, dos quais ela um dia foi parte. Nessa condição, a relíquia ao mesmo tempo provoca e convoca o sujeito que a admira a um desafio, na forma de uma analogia: ser protagonista como o foi seu portador originário (o santo, o herói, o gênio). Nessa complexa potência, a relíquia carrega um valor pedagógico: ao evocar, provocar, convocar, ela ensina e forma.

O fato de perder-se no tempo a prática dos seres humanos de colecionarem objetos (BLOM, 2003) sob os mais diversos propósitos, não parece bastante para esgotar os sentidos dessa prática. O Museu situa-se em parte como uma instituição em continuidade a esse mesmo hábito, sob a justificativa expressa de preservação e cultivo da memória social. Segundo o International Council of Museums (ICOM), em um sentido lato, seu objetivo é "[...] investigar, perpetuar, perenizar e transmitir à sociedade o patrimônio cultural e natural mundial, presente e futuro, tangível e intangível" (ICOM, s.d., n.p.). A variedade de modos e de sentidos com que o Museu realiza tal propósito geral, porém, evidencia a complexidade de sua tarefa. 
A museóloga Waldisa Rússio (s.d., p. 7) define a Museologia "[...] como "ciência do fato museal ou museológico' e este como 'a relação profunda entre o homem, sujeito que conhece e o objeto, parte da realidade, à qual também pertence o homem e sobre a qual ele tem o poder de agir'”. Desse modo, o museu é o cenário institucionalizado onde o fato museal acontece. A autora reafirma assim a museologia como a ciência que estuda a relação entre o homem e o mundo, mediada pelos objetos musealizados.

Ainda segundo a mesma autora, “[...] a musealização do objeto é um processo de fragmentação do real para melhor conhecê-lo, uma fragmentação que tenta reconstituir o todo" (RÚSSIO, s.d., p. 17). Para ela: “Quando nós musealizamos objetos, ou seja, quando recolhemos objetos como testemunhos, nós os musealizamos porque eles são testemunhos, são documentos e têm fidelidade. Eles são, na verdade, testemunhos do homem e do seu meio" (RÚSSIO, 1984, p. 61).

Nessa proposição, a musealização dos objetos implica um discurso específico no qual a atribuição de valor a certos objetos e não a outros funda uma noção de patrimônio e de memória, provocando uma identidade social. Assim, ela se justifica até o ponto em que alguma materialização dos símbolos seja um recurso pedagógico suficiente para a socialização das novas gerações no interior das referências identitárias do grupo social, cultural, nacional. Essa concepção de que os significados e os sentidos atribuídos aos objetos musealizados, portanto institucionalizados, conferem reconhecimento e identidade cultural a uma comunidade, postula, inerentemente, a vitalidade do diálogo do Museu com a comunidade.

Não obstante, essa função de musealização dos objetos inscreve a prática museológica no limite entre essa relação vital com a comunidade e a instauração do fetiche. Com efeito, não são raros os exemplos de Museus que seguem reduzindo sua prática à exclusiva função de guardar, preservar e ocasionalmente exibir objetos tidos como significativos, ordenados segundo classes (naturais, históricos, artísticos). Nessas condições, paradoxalmente, a musealização dos objetos, quanto mais intangibilidade lhes confere, por inevitável efeito, mais os envolve com a aura de relíquia e, no limite, de fetiche. O caráter religioso, não casual, implicado nessa nomenclatura revela grande parte de sua essência ${ }^{4}$. A fusão de elemento religioso com elemento econômico corrobora essa ideia de uma economia religiosa presente subliminarmente como memória no Museu.

A questão que se coloca é a das condições pelas quais um Museu, no limite desse reducionismo, poderia cumprir uma função educativa. Pode-se sustentar, por hipótese, que o 
cumprimento dessa função educativa de formação cultural dependeria em grande parte da explicitação do processo de produção dos objetos musealizados exibidos, e da construção de novas narrativas a partir destes objetos, o que pode ser realizado em cooperação com a Universidade.

\section{MUSEU E PRODUÇÃO CULTURAL}

Todo objeto histórico ou de arte pode ser considerado sob duplo aspecto: como um produto acabado e inerte - o objeto tal como atualmente exposto; e do ponto de vista da exibição também do seu processo histórico e cultural de produção. Nessa condição, ele é mostrado como a síntese material de uma certa experiência individual e coletiva que o produziu: manifestação histórica de uma concepção da realidade e de uma prática social subjacentes à sua produção. Sob essa lógica, o objeto histórico ou de arte é mostrado como um produto do trabalho humano. Rússio explicita, em sua argumentação, a esse propósito:

[...] o homem e o meio, o ambiente físico natural, o ambiente físico alterado pelo homem, transformado, urbanizado, as criações de seu espírito, todo seu ideário, seu imaginário, toda a riquíssima gama de intervenções, de atuações do homem ou de, simplesmente, percepções do homem [que], para nós, são nada mais do que trabalho. Então resulta que, para o museólogo, cultura é essencialmente fazer e viver, ou seja, cultura é resultado do trabalho do homem, seja ele um trabalho intelectual, seja ele um trabalho intelectual refletido materialmente na construção concreta. [...] nós temos feito uma exploração que me parece um pouco superficial da questão patrimônio, colocando simplesmente que o patrimônio é um conjunto de bens, e o patrimônio cultural é um conjunto de bens culturais, esquecendo que eles são bens na medida em que o homem atribui a eles significado (RÚSSIO, 1984, p. 61).

Sob essa concepção ampla, pode-se dizer que o objeto de interesse do Museu é, em última instância, o próprio ser humano em toda a amplitude de seu processo social de produção e de reprodução histórica e cultural. Essas considerações remetem à teoria da cultura na qual esse conceito, se reduzido ao campo abstrato das formas simbólicas, não aparece como o fundante, muito menos o historicamente originário. Não por acaso os estudos semânticos registram que a palavra "cultura" deriva originalmente de uma concreta ação no campo econômico: remete ao trabalho com a terra e com a domesticação de animais. Esse conceito de cultura relacionado ao processo produtivo e, portanto, ao criativo trabalho humano evidencia 
sua potência no fato da transformação incessante das relações humanas e a consequente compreensão sempre mais ampla da realidade que ele provoca.

Na segunda metade do século XIX, desde os primeiros movimentos da antropologia cultural, pela qual cada cultura passou a ser vista como singularidade dotada de estrutura, funcionamento, modo de produção e de ordenamento simbólico específicos, o termo ganhou nova abrangência, e cultura passou a referir-se especificamente a esse campo das formas simbólicas, entendida como

[...] criação coletiva da linguagem, da religião, dos instrumentos de trabalho, das formas de habitação, vestuário e culinária, das manifestações de lazer, da música, da dança, da pintura e da escultura, dos valores e das regras de conduta, dos sistemas de relações sociais, particularmente os sistemas de parentesco e as relações de poder. A partir de então, a cultura é compreendida como o campo no qual uma comunidade institui as relações entre seus membros e a natureza, conferindo-lhes sentido ao elaborar símbolos e signos, práticas e valores, ao definir para si própria o possível e o impossível, a linha do tempo (passado, presente e futuro), as distinções no interior do espaço, o verdadeiro e o falso, o belo e o feio, o justo e o injusto, o permitido e o proibido, a relação com o visível e o invisível, com o sagrado e o profano, a Guerra e a paz, a vida e a morte (CHAUÍ, 2006, p. 131).

Sob esse conceito de referência, que se apresenta como crítico, todo objeto cultural (re)aparece como uma unidade sintética de um acervo de conhecimentos. Em síntese, nessa acepção, o ser humano é e produz cultura. Sob esse conceito, a cultura deixa de ser vista como privilégio de uma elite: nem privilégio de produção, nem de consumo, nem de deleite; assim, não é um marcador de diferenciação de classes. A cultura é vista propriamente como fenômeno fundante da existência, produzida pela necessidade vital de conservar-se, reproduzir e desenvolver a vida em comunidade (DUSSE, 2000). A cultura mobiliza, pois, uma comunidade humana, uma sociedade, em que o sujeito-produtor-cultural é capaz de reconhecer-se e reconhecê-las como propriedade sua e de outros que virão. Nesse sentido, a cultura sempre agrega um conjunto de valores que permitem articular a memória do passado a algo a ser dito ao futuro, afirmando continuidades e descontinuidades, promovendo mudanças. Nessa direção, Guy Debord (1997, p. 120) afirmará que “[...] a cultura é o lugar da busca da unidade perdida”.

Tal noção radical de cultura implica um conjunto de fenômenos que devem ser identificados não apenas como testemunhos inertes da vida de uma certa comunidade, de uma certa sociedade, mas como afirmações de que alguma transcendência histórica foi possível lá e continua a ser possível aqui. Em outras palavras, afirmações fundantes de alguma tradição, no 
sentido literal: de algo-a-ser-dito para a formação das gerações futuras; elementos transmissíveis; inscrita também no campo educacional, portanto.

A questão que se coloca é a de como as gerações que se seguirão à da produção cultural realizada acolherá, processará e significará o acervo coletado, que sentidos e usos lhe atribuirão. O tema remete a Giorgio Agamben (2017) à vista do inventário extraordinário que esse filósofo italiano fez dos sentidos de usos dos corpos e, por extensão, de usos dos produtos do trabalho corporal, ou seja, da cultura.

Ortega y Gasset, igualmente, agrega sentidos sutis a esse mesmo conceito de produção cultural, que merecem consideração: "A elaboração humana de suas necessidades, o que o homem faz com elas, isso é a cultura" (ORTEGA Y GASSET, 1967, p. 220, grifos do autor). E, simultaneamente,

[...] se faz a si mesmo com as coisas que lhe são oferecidas, faz com elas vida, a sua vida; [...] seu destino concreto é impor ao real seu projeto pessoal, dar sentido ao que não tem, [...] converter isso que simplesmente 'há ali ao meu redor' em verdadeiro mundo, em vida humana pessoal" (ORTEGA Y GASSET, 1967, p. 223, grifos do autor).

Esse "ali ao meu redor" se refere ao seu clássico e fundante conceito de "circunstância", que, em Ortega y Gasset, evidencia o modo como o entorno se transforma - tal como o sentido dos objetos musealizados, por exemplo, inseparáveis da circunstância que os envolve. Contempla o entorno não reduzido à paisagem natural e social: "Eu estou definido pela minha circunstância, mas minha circunstância não me define" (ORTEGA Y GASSET, 1967, p. 223). Nesse sentido, cabe criticar a cultura institucionalizada, suspeitando dos sentidos que the foram atribuídos como configurações culturais. Por isso, quanto mais inteligência do sujeito frente ao objeto musealizado, mais chances de uma percepção que remeta criticamente às circunstâncias originárias daquela produção cultural e, consequentemente, de concretização de um novo conhecimento. Priorizar a presença do objeto, nessa perspectiva, não elimina, pois, a função do sujeito; ao contrário, o requer com mais intensidade, até porque, como afirma Paulo Freire: "Conhecer é tarefa de sujeitos, não de objetos. E é como sujeito e somente enquanto sujeito, que o homem pode realmente conhecer" (FREIRE, 1983, p. 27).

Esse vínculo entre a cultura como manifestação dos sentidos de uma sociedade, em uma determinada época, e o trabalho de atualização desses sentidos por meio de sua exposição presente, é o que permite uma certa tomada de consciência (prise de conscience, dirá Merleau- 
Ponty (1999) no Prefácio de sua Fenomenologia) da sociedade atual por si mesma. O Museu pode ser o lugar dessa afirmação e dessa tomada de consciência, onde sujeitos e comunidades poderão reivindicar novos sentidos para os objetos e para os sujeitos que os produziram, compartilhando, dessa forma, a responsabilidade de preservar e comunicar o patrimônio cultural. Rússio (1984, p. 61) dirá que “[...] patrimônio cultural é um conjunto de bens culturais que são bens na medida em que o homem atribui a eles significados. E a atribuição de significados é um dado estritamente cultural".

As narrativas criadas no Museu e fora dele difundidas são, desse modo, resultados de um processo de seleção baseado em apreciações que se estendem no amplo espectro entre as preferências mais particulares e os critérios epistemológicos mais universais. Por isso, na relação entre o sujeito singular e a cultura objetivamente exposta no museu, é o sujeito quem decidirá sobre os sentidos que podem ser preservados e os novos sentidos que podem ser adotados. Cabe ao Museu apenas fornecer-lhe as condições necessárias para essa decisão.

\section{MUSEU, INDÚSTRIA CULTURAL E SEMIFORMAÇÃO}

Adorno (2000) cunhou o conceito de indústria cultural para referir-se ao processo de produção cultural operado sob a lógica do mercado. A premissa argumentativa que fundamenta o conceito é a de que os bens físicos e os bens culturais são moldados por uma mesma lógica social. O núcleo central do conceito reside na crítica ao reducionismo da cultura à mercadoria. $\mathrm{O}$ conceito de indústria cultural encontra seu fundamento na percepção desse processo de conversão das criações estéticas em mercadoria. Trata-se de uma denúncia do quanto o potencial criativo de inovação e de transformação da cultura é devorado pela lógica reprodutiva do mercado, quando submetida ao seu modo de funcionamento. A indústria cultural é um meio de controle e de reprodução simbólica, mas simultaneamente a arte e as demais manifestações culturais podem levar a cabo o potencial de distorção crítica desse controle. Na medida em que o conceito de indústria cultural implica e abrange os meios de comunicação, ele antecipa o conceito de espetáculo, desenvolvido posteriormente por Guy Debord:

O indivíduo que foi marcado pelo pensamento espetacular empobrecido, mais do que por qualquer outro elemento de sua formação, coloca-se de antemão a serviço da ordem estabelecida, embora sua intenção subjetiva possa ser o oposto disso. Nos pontos essenciais, ele obedecerá à linguagem do espetáculo, a única que conhece, aquela que lhe ensinaram a falar. Ele pode querer 
repudiar essa retórica, mas vai usar a sintaxe dessa linguagem. Eis uns dos aspectos mais importantes do sucesso obtido pela dominação espetacular (DEBORD, 1997, p. 191).

Adorno desenvolve o tema mediante reapropriação da teoria marxista de que o homem é produto de seu trabalho, sendo sua subjetividade moldada pelos modos de produção e pelas relações de produção de seu tempo (MARX; ENGELS, 2007). Os desdobramentos dessa tese com a produção da arte são imperativos, uma vez que a produção artística e cultural é ela mesmo material, não só no sentido de que produz objetos e materialidades (considerando-se performances e manifestações culturais efêmeras como fenômenos culturais materiais), mas também no sentido de que trabalha com bens materiais de produção, sendo uma prática real e elemento de um processo social material.

$\mathrm{Na}$ teoria marxiana (que, neste ponto, se mostra como desdobramento conceitual da teoria hegeliana do reconhecimento), o fato de o produto do trabalho ser arrebatado das mãos do trabalhador-produtor pelo proprietário dos meios de produção resulta em que o trabalhadorprodutor seja impossibilitado de ver suas próprias qualidades de produtor (no limite: impossibilitado de ver-se em sua identidade humana de produtor), por não ser proprietário do seu produto. Nesse sentido, o valor de uso do seu produto, nele depositado, resulta convertido (reduzido) ao valor de troca, segundo o interesse do proprietário (MARX, 2014). Esse fato de o trabalhador-produtor não poder se reconhecer no produto por ele produzido (posto que agora o produto do seu trabalho foi reduzido à mercadoria) funda o efeito de esta adquirir um poder que parece ser inerente a ela, agindo, assim, de volta sobre (e contra) o produto, e por ele contra o produtor, com poder de fascínio e de domínio. O caráter mágico dessa inversão de poderes confere a esse processo um sentido religioso - ilusório na sua factualidade; real nos seus efeitos psicológicos e, consequentemente, políticos e culturais: o fetiche.

As relações de produção, que, no capitalismo, são as de exploração do proletariado pela burguesia, tornam-se dissimuladas, aparentando ser relações entre coisas (ADORNO, 2000). O trabalho termina, assim, reduzido a fundamento de uma interação simbólica que se volta contra o próprio trabalhador. No caso de todas as mercadorias, mas de modo especial nas mercadorias culturais, produtos da indústria cultural, o fetichismo consiste propriamente no fato de o sujeito enxergar um suposto valor intrínseco na mercadoria quando, na verdade, todo valor de troca ali existente, enquanto mercadoria, é efeito de um esforço comercial de terceiros para promover e produzir essa ilusória identificação no sujeito que a produziu. 
Esse conceito de mercantilização da cultura é um dos principais a sustentar o conceito de indústria cultural (ADORNO, 2000) e implica o reconhecimento de um sistema que permeia diversas esferas da cadeia produtiva. A análise de Adorno sobre a crescente mercantilização dos bens culturais (no limite, da cultura) envolve, pois, o reconhecimento de uma transformação estrutural da cultura. A mercantilização dá-se desde o momento da produção, na qual os produtos já são concebidos como mercadorias a serem trocadas no mercado, com desejável poder de ação sobre os sujeitos consumidores, aptas para satisfazerem alguma necessidade evidentemente substitutiva. A esse propósito, assim se expressou Bárbara Freitag (1986, p. 72): “[...] a 'indústria cultural' é a forma sui generis pela qual a produção artística e cultural é organizada no contexto das relações capitalistas de produção, lançada no Mercado e por este consumida". Quando a produção simbólica, própria do processo da cultura, se distancia do saber popular, que é o seu fundamento em última instância, e se aproxima do campo de interesses do mercado, encontram-se dadas as bases para consolidação do que, para Adorno, constitui o processo de semiformação.

O conceito de semiformação (Halbbildung), não obstante ser um dos conceitos centrais da Dialética do Esclarecimento (ADORNO; HORKHEIMER, 2006) é frequentemente mal compreendido e mal empregado. O conceito original de referência é Bildung, que, na língua alemã, tem um significado análogo ao de Kultur, visto que este se refere mais propriamente ao sistema objetivo de relações humanas, enquanto Bildung se refere aos processos subjetivos de "formação" (dos sujeitos) dentro da Kultur. Na língua alemã, Bild significa "quadro", de modo que "formação" tem uma certa conotação daquilo que, na língua portuguesa, se designa como "enquadramento".

Hegel (1990) foi quem originariamente elaborou a ideia de que a formação tem como principal fundamento e mediação o trabalho (a atividade pela qual os seres humanos podem reconhecer-se como humanos). O conceito passará por Marx, que preliminarmente reconheceu a grandeza da Fenomenologia hegeliana em ter compreendido a autogeração do homem "como resultado do seu próprio trabalho" (MARX, 1974, p. 49), mas criticou seu mestre por ter restringido o conceito de trabalho a algo "abstrato, espiritual” (MARX, 1974, p. 50) e não como "trabalho alienado, no interior da alienação" (MARX, 1974, p. 49) do modo de produção capitalista. Ora, é precisamente essa condição de alienação radical que Adorno (juntamente a Horkheimer) designará de "barbárie" na Dialética do Esclarecimento e na entrevista $A$ Educação contra a Barbárie (ADORNO, 1995); é também o que explica por que a formação 
nos moldes de uma Kultur de barbárie resulta em uma Halbbildung e não propriamente em uma Bildung.

Como salientou Bruno Pucci (1994, p. 32), a Halbbildung não pode ser compreendida somente como um processo cultural "[...] que não teria se construído por completo”. O equívoco provém do fato de que a primeira parte da palavra ( $\mathrm{Halb}$, em alemão, que corresponde a semi, em grego, - que literalmente significa "meio", "metade") sugere imediatamente um sentido quantitativo, mas é qualitativo. Por isso, antes que uma meia-formação, a Halbbildung é propriamente a deformação que impede e degrada a formação cultural autêntica. Wolfgang Leo Maar (2003), um dos mais autorizados leitores e tradutores de Adorno, indica que a Dialética do Esclarecimento expressa a ameaça à formação da subjetividade como Bildung, presente em sua redução à Halbbildung pela indústria cultural, entre outros fatores.

Para Adorno (1996), com efeito, o semientendido e o semiexperimentado não representam um processo de formação incompleto, mas, sim, o inimigo letal desse processo, já que, nas palavras de Wolfgang Leo Maar (2003, p. 463), “[...] no mundo reconstruído o sujeito semiformado toma-se como sujeito do mundo que meramente reproduz. Para ele a construção parece 'natural', mas é uma 'segunda' natureza'. Observa-se, nessa passagem, como Adorno, seguindo a mesma inspiração marxiana, estende o próprio campo da semiformação, agora também para o plano da consciência, o que finalmente é o fundamento do conceito de semiformação e de sua indispensável superação. Assim expõe Adorno:

O esclarecimento como consciência de si, como autoconscientização, [...], é condicionado culturalmente e, nos termos a indústria cultural, limita-se a uma "semiformação", a uma falsa experiência restrita ao caráter afirmativo, ao que resulta da satisfação provocada pelo consumo dos bens culturais. Esta é uma satisfação real [...]. Mas é uma satisfação que trava as possibilidades da experiência formativa. [...]. Pelo fenômeno da indústria cultural, portanto, a dominação no plano da subjetividade, até mesmo em aspectos mais subjetivos, seria condicionada à estrutura social (MAAR, 1995, p. 23).

Nesse sentido, é significativo que os espanhóis tenham adotado a tradução de Halbbildung como $(P)$ seudoformación ${ }^{5}$, termo que permite expressar fortemente essa inautenticidade.

A crítica fecha seu arco com a afirmação de Adorno (apud MAAR, 2003, p. 469) de que a “[...] semiformação é o espírito tomado pelo caráter de fetiche da mercadoria”. No limite, é manifestação da barbárie. Com efeito, em A Educação contra a Barbárie, Adorno (1995, p. 155) definirá barbárie como “[...] algo muito simples, ou seja, que, estando na civilização do 
mais alto desenvolvimento tecnológico, as pessoas se encontrem atrasadas de um modo particularmente disforme em relação a sua própria civilização". Essa definição de barbárie, não como conceito essencializado, mas, sim, relativo às possibilidades civilizatórias concretamente dadas, revela-se notavelmente atual e perene e impõe uma agenda permanente de formação cultural.

Adorno e Horkheimer (2006) indicam como sendo um efeito inerente à mercantilização da cultura a perda de liberdade no momento da reprodução. Nesse sentido, não por acaso, o conceito indústria cultural é apresentado em Dialética do esclarecimento a partir de uma contextualização ampla que os autores realizam em relação ao desenvolvimento da humanidade. Os aspectos subjetivos e objetivos da crítica cultural são sintetizados por meio do conceito indústria cultural, que diz respeito aos processos econômicos que transformaram a cultura e a arte em mercadoria e aos processos psíquicos que transformaram o homem moderno em um consumidor dessas mercadorias. Os autores, nesse texto, vinculam a arte e a cultura a aspectos econômicos e psicológicos, cujos sistemas estão dialeticamente interrelacionados, mediante múltiplas determinações recíprocas. Eles apresentam, ademais, uma narrativa sobre a história da civilização a partir do desenvolvimento da razão, em que a racionalidade humana seria uma resposta à necessidade de autoconservação. Como desdobramento dessa necessidade fundamental, analisam uma série de manifestações culturais humanas que, segundo eles, foram criadas com o intuito de organizar o mundo exterior, permitindo ao homem dominar a natureza: a magia, o mito, a filosofia, a ciência, as religiões modernas, o capitalismo e a arte. Todos esses aspectos da cultura humana aparecem, assim, como criações da civilização, que organizaram o mundo em diferentes momentos históricos, por meio da razão.

Chega-se, assim, à tese principal da obra Dialética do esclarecimento: que a razão humana desenvolve-se mediante a contradição, pela qual, ao mesmo tempo que cria artifícios que permitem o progresso da humanidade garantindo a sua sobrevivência, carrega a possibilidade de gerar, em seu interior, a própria irracionalidade, uma tendência à autodestruição, que os autores designam barbárie (ADORNO; HORKHEIMER, 2006).

No excurso II da mesma obra, os autores opõem-se à perspectiva kantiana segundo a qual os homens viriam ao mundo munidos de um aparelho cognitivo que estrutura sua percepção da realidade, conferindo unidade entre a apreensão de cada um e a própria realidade. Em contraponto a Kant, os autores entendem que a percepção humana é fruto das condições sociais de sua existência, e que a realidade e sua apreensão são inseparáveis da dominação à 
qual o sujeito é submetido. Desse modo, a qualidade de vida e de trabalho condiciona a percepção que se tem sobre o mundo, ou seja, essa percepção é mediada também pela cultura. Se a cultura precisa ser ensinada, apreendida, transmitida, comunicada, cumpre um paradoxo: ao mesmo tempo que determina, realiza seu potencial emancipador. Assim sendo, para Adorno, segundo Maar (1995, p. 19), “[...] a formação que conduziria à autonomia dos homens precisa levar em conta as condições a que se encontram subordinadas a produção e a reprodução da vida humana em sociedade e na relação com a natureza”. É nesse sentido que a formação deve levar em conta a cultura.

Como compreender, então, esse conjunto de significações da cultura que promovem a capacidade humana de questionar e emancipar-se? O reconhecimento do seu processo de realização é condição indispensável para seu desenvolvimento. Sustentamos aqui a hipótese de que o Museu cumpriria função indispensável nesse reconhecimento.

Esse tema da formação do sujeito na sua relação com a cultura, de modo especial pela mediação do Museu, remete novamente à Fenomenologia de Merleau-Ponty (1999), que considera a ambiguidade do sentido ao mesmo tempo imanente e transcendente à produção cultural, às contingências da realidade e à criatividade do sujeito. A Fenomenologia merleaupontyana enfatiza a importância da percepção no ato de conhecer, movimento que se espera ser praticado no Museu, posto que inerente à situação em que o sujeito se depara com um objeto inusitado. Justamente ao apropriar-se das relações sugeridas pelo objeto e suas circunstâncias de produção e exibição, o sujeito encontra as razões dessa sugestão. Esse movimento entrelaça os sentidos disparados pela cultura por meio da provocação às qualidades estéticas da obra, enquanto evoca significados socialmente compartilháveis.

Com efeito, o Museu é antes de tudo uma experiência perceptiva. No Museu convencional, uma das primeiras experiências possíveis costuma estar relacionada à visão. $\mathrm{O}$ estímulo visual vem acompanhado de uma síntese que não se fecha em si, mas abre um horizonte de possibilidades. A consciência do sujeito é, então, dirigida para algo que se abre. Esse sistema de aparências, constituído pelo objeto de arte e pela sua disposição espacial, faz com que nenhuma análise verbal esgote suas possibilidades significativas, transferindo as possibilidades formais e conceituais do objeto para uma esfera de reconhecimento cultural. Nela, o sujeito identifica aspectos subjetivos e objetivos do mundo que o cerca. "A cultura nunca nos oferece significações absolutamente transparentes; a gênese do sentido nunca está 
terminada" (MERLEAU-PONTY, 1999, p. 70). O sentido é construído, assim, sob a atmosfera multissensorial na qual o objeto se apresenta. Trata-se de uma atividade perceptiva que, segundo Merleau-Ponty (1999), remete às experiências sensíveis mais originárias. Ao mesmo tempo, consiste em uma atividade formativa que, segundo Adorno (1995), como visto, remete à apropriação subjetiva da cultura.

A complexidade da produção crítica contemporânea de arte, comumente pautada mais em processos do que em produtos, com efeito, exige por parte do público disposição e movimentos investigativos e reflexivos. Nesses casos, o valor cultural do objeto de arte está mais nas ideias (do autor e do apreciador) e menos na produção, o que permite ao objeto de arte apresentar-se mais como um repertório de sentidos humanos e ideais de emancipação, e menos como mercadoria.

Contudo, se a arte pode desprover-se do objeto, tornando-se dependente e existente no e pelo discurso, como a realidade relacionada a ela é expressa? Esse repertório de sentidos humanos é construído e caminha conforme o quê? São ditos pelos interesses dos grupos que organizam a vida social? Nesse caso, existe uma necessidade de superação da cultura? "O museu foi o local mais apropriado para reproduzir no indivíduo simultaneamente o distanciamento dos fatos" (MARCUSE, 1997, p. 129). O Museu coloca à disposição da sociedade a cultura produzida e possibilita ao sujeito a liberdade de pensar sobre a transitoriedade de sentidos. Não há, nesse caso, condicionamento da consciência.

Adorno caminhou por aí ao explorar o pensamento de uma experiência formativa que, segundo Maar (1995, p. 25), “[...] não se esgota na relação formal do conhecimento - das ciências naturais, por exemplo - mas implica uma transformação do sujeito no curso de seu contato transformador com o objeto na realidade". O Museu, ao mesmo tempo que preserva o patrimônio de uma sociedade, transforma-o quando amplia suas possibilidades significativas, reflexivas e discursivas para o público.

\section{CONSIDERAÇÕES FINAIS: MUSEU, UNIVERSIDADE E FORMAÇÃO CULTURAL}

Museus que sigam restringindo sua prática à exclusiva função de guardar, preservar e ocasionalmente exibir objetos fetichizados ao modo da mercadoria convertem-se eles próprios em instituições reificadas, objetos de mercado, casas de espetáculo e entretenimento mais do 
que de formação. Museus que proporcionam a apropriação da cultura como fenômeno do mundo, em sua face local e simultaneamente universal, como produtos complexos do trabalho humano, efetivamente ensinam (in-signum - em sua radicalidade etimológica: imprimem um sinal) e cumprem função de formação cultural. Tal experiência formativa é a única que permite que o sujeito se aproprie subjetivamente da cultura enquanto dialoga com diferentes fontes estéticas.

O Museu é testemunha e protagonista da realidade histórica e cultural. Por isso, mais do que exibir um patrimônio, ele permite e torna inteligível a relação entre objetos, entre os sujeitos que os produziram, e entre os discursos que fazem a sua mediação, propondo hipóteses polissêmicas sobre o que (re)significam. É um território e uma temporalidade que maneja símbolos de identidades. Por conseguinte, enfatiza menos a sua capacidade de reproduzir as semelhanças e as diferenças entre os grupos sociais e mais a sua competência em reformular o conceito de patrimônio cultural como um processo social que reestrutura e redefine sentidos.

Este texto aponta para uma exposição crítica dessas oportunidades de formação cultural, sustentando a indispensável articulação entre a educação e a cultura institucionalizada nos Museus. Nem o Museu nem a Universidade estão isentos das pressões do Mercado de reduzirem suas funções a serviço da indústria cultural e, portanto, a produzirem alienação e semiformação. Não obstante, do ponto de vista da Teoria Crítica, é possível e eticamente obrigatório ao Museu atuar no contrafluxo da indústria cultural. Atuando de modo colaborativo, Universidade e Museu podem cumprir de modo mais radical a formação cultural dos sujeitos e, assim, cumprir uma função cultural e política contra-hegemônica.

\section{REFERÊNCIAS}

ADORNO, Theodor Ludwig Wiesengrund. Prismas. La critica de la cultura y la sociedade. Barcelona: Ediciones Ariel, 1962.

ADORNO, Theodor Ludwig Wiesengrund. A Educação contra a Barbárie. In: ADORNO, Theodor Ludwig Wiesengrund (Org.). Educação e emancipaçãa. Tradução de Wolfgang Leo Maar. Rio de Janeiro: Paz e Terra, 1995. p. 155-168.

ADORNO, Theodor. Teoria da Semicultura. Educação \& Sociedade, Campinas, n. 56, ano XVII, p. 388-411, dez. 1996. 
ADORNO, Theodor Ludwig Wiesengrund. A Indústria Cultural. 2000. Disponível em: https://edisciplinas.usp.br/pluginfile.php/4848463/mod_resource/content/1/Adorno_Industria Cultural.pdf. Acesso em: 20 maio 2020.

ADORNO, Theodor; HORKHEIMER, Max. Sociológica. Tradução Víctor Sánchez de Zavala. Madrid: Taurus, 1966.

ADORNO, Theodor; HORKHEIMER, Max. Dialética do esclarecimento. Rio de Janeiro: Jorge Zahar, 2006.

AGAMBEN, Giorgio. O uso dos corpos (Homo Sacer, IV, 2). São Paulo: Boitempo, 2017.

ANDRADE, Mário de. Museus Populares. Revista do Patrimônio Histórico e Artístico Nacional, Rio de Janeiro, n. 31, p. 127-131, 2005.

BENJAMIN, Walter. Obras Escolhidas. Magia e Técnica, Arte e Política. São Paulo: Brasiliense, 1985.

BLOM, Philipp. Ter e manter: uma história íntima de colecionadores e coleções. Rio de Janeiro: Editora Record, 2003.

CAMPBELL, Joseph. Primitive Mithology. The Masks of God. v. 1. New York: Penguin Books, 1976.

CHAUÍ, Marilena. Cidadania cultural: o direito à cultura. São Paulo: Fundação Perseu Abramo, 2006.

DEBORD, Guy. A Sociedade do espetáculo. Rio de Janeiro: Contraponto, 1997.

DECLARAÇÃO DE BOLOGNA. 1999. Disponível em: http://www.magnacharta.org/resources/files/BOLOGNA_DECLARATION.pdf. Acesso em: 19 out. 2019.

DUSSEL, Enrique. Ética da libertação. Na idade da globalização e da exclusão. Petrópolis: Vozes, 2000.

ELIADE, Mircea. Tratado de História das Religiões. Lisboa: Cosmos, 1977.

ELIADE, Mircea. Aspectos do Mito. Lisboa: Edições 70, 1986.

FREIRE, Paulo. Extensão ou comunicação. Rio de Janeiro: Paz e Terra, 1983.

FREITAG, Barbara. A Teoria Crítica: ontem e hoje. São Paulo: Brasiliense, 1986.

HEGEL, Georg Wilhelm Friedrich. Fenomenologia do Espírito. Petrópolis: Vozes, 1990.

HOUAISS. Fetiche. Dicionário da Língua Portuguesa. Rio de Janeiro: Objetiva, 2004.

ICOM. International Council of Museums. Misiones y objetivos. s.d. Disponível em: https://icom.museum/es/sobre-nosotros/misiones-y-objetivos/. Acesso em: 2 set. 2019.

ISHIHARA-BRITO, Reiko; RODRÍGUEZ GUAJÁN, Pakal B’alam. Reliquias, artefactos y herramientas educativas: conservación del patrimonio cultural por la educación pública en el 
Museo. Revista de Antropología Chilena, Chungará (Arica), v. 44, n. 3, p. 445-453, set. 2012.

MAAR, Wolfgang Leo. Adorno, semiformação e educação. Educação \& Sociedade, Campinas, v. 24, n. 83, p. 459-476, ago. 2003.

MAAR, Wolfgang Leo. À guisa de introdução: Adorno e a experiência formativa. In:

ADORNO, Theodor Ludwig Wiesengrund (Org.). Educação e emancipação. Rio de Janeiro: Paz e Terra, 1995. p. 11-28.

MARCUSE, Herbert. Cultura e sociedade. Rio de Janeiro: Paz e Terra, 1997.

MARX, Karl. Manuscritos Econômico-filosóficos. Terceiro Manuscrito. São Paulo: Victor Civita, 1974.

MARX, Karl. O Capital: crítica da economia política. 33. ed. Rio de Janeiro: Civilização Brasileira, 2014. Livro I, v 1.

MARX, Karl.; ENGELS, Friedrich. A Ideologia Alemã: crítica da mais recente filosofia alemã em seus representantes Feuerbach, B. Bauer e Stirner, e do socialismo alemão em seus diferentes profetas. São Paulo: Boitempo, 2007.

MERLEAU-PONTY, Maurice. Fenomenologia da percepção. Tradução Carlos Alberto Ribeiro de Moura. São Paulo: Martins Fontes, 1999.

ORTEGA Y GASSET, José. Meditações do Quixote. São Paulo: Livro Ibero-Americano, 1967.

PUCCI, Bruno. Teoria crítica e educação. In: PUCCI, Bruno (Org.). Teoria crítica e educação: a questão da formação cultural na Escola de Frankfurt. 2. ed. Petrópolis: Vozes; São Carlos: Editora da UFSCar, 1994. p. 11-58.

PUCHNER, Martin. O mundo da escrita. Como a literatura transformou a civilização. São Paulo: Companhia das Letras, 2019.

RÚSSIO, Waldisa. Formação do Museólogo: por que em nível de Pós-Graduação?. São Paulo: Fundo Waldisa Rússio; Instituto de Estudos Brasileiros da Universidade de São Paulo - IEB/USP, s.d.

RÚSSIO, Waldisa. Texto III. In: ARANTES, Antonio Augusto (Org.). Produzindo o passado: estratégias de construção do patrimônio cultural. São Paulo: Brasiliense, 1984. p. 59-78.

\section{NOTAS}

${ }^{1} \mathrm{O}$ Mouseion, santuário grego consagrado às Musas, filhas de Zeus e de Mnemosyne (a deusa da Memória), protetoras das Ciências e das Artes, tanto servia para o culto quanto para práticas de artes, ciência e filosofia. Esse modelo de instituição, que teve a mais alta expressão na Alexandria, desde o século III a.C., cujo Mouseion continha a famosa Biblioteca de Alexandria (PUCHNER, 2019), cumpria, efetivamente, uma função de formação cultural. 
${ }^{2}$ Reporta-se aqui à distinção posta por Walter Benjamin (1985), entre experiência (Erfahrung) e vivência (Erlebnis), na qual a primeira se refere ao socialmente compartilhável e a segunda ao que, sendo tão íntimo e singular, resulta no limite indizível e incompartilhável.

${ }^{3}$ A Declaração de Bologna (1999), assinada por ministros de educação de 29 países europeus e, posteriormente, referendada por outras duas dezenas de países, teve como objetivo, dentre outros, "[...] elevar a competitividade internacional do sistema europeu do ensino superior". Disponível em: http://www.magnacharta.org/resources/files/BOLOGNA DECLARATION.pdf. Acesso em: 19 out. 2019.

${ }^{4} \mathrm{O}$ vocábulo fetiche é cognato de feitiço e feiticeiro e, como estes, derivado do adjetivo latino facticius, a, um (que significa "artificial, não-natural, imitativo, onomatopaico", segundo Houaiss (2004), e remete igualmente a um "trabalho" espiritual "feito" contra ou a favor de alguém.

${ }^{5}$ Assim argumenta Víctor Sánchez de Zavala, consagrado tradutor da obra de Adorno para a língua espanhola: "Normalmente traduciremos Halbbildung (literalmente, semiformación o semicultura), que de ordinario significa seudoerudición, por seudoformación, pues este trabajo se apoya principalmente en su sentido etimológico; y en algunos lugares - como en éste - por seudocultura. Formación y formación cultural, según los casos, verterán Bildung, que corrientemente significa, además, enseñanza, educación, cultura, etc.” (ADORNO; HORKHEIMER, 1966, p. 175).

Recebido em: 15/06/2020

Aprovado em: 21/07/2020 